$11-1-2012$

\title{
Examining Growth with Statistical Shape Analysis and Comparison of Growth Models
}

Deniz Sigirli

Uludag University, Gorukle/Bursa, Turkey

Ilker Ercan

Uludag University, Görükle/Bursa, Turkey

Follow this and additional works at: http://digitalcommons.wayne.edu/jmasm

Part of the Applied Statistics Commons, Social and Behavioral Sciences Commons, and the Statistical Theory Commons

\section{Recommended Citation}

Sigirli, Deniz and Ercan, Ilker (2012) "Examining Growth with Statistical Shape Analysis and Comparison of Growth Models," Journal of Modern Applied Statistical Methods: Vol. 11 : Iss. 2 , Article 19.

DOI: $10.22237 /$ jmasm/1351743480

Available at: http://digitalcommons.wayne.edu/jmasm/vol11/iss2/19

This Regular Article is brought to you for free and open access by the Open Access Journals at DigitalCommons@WayneState. It has been accepted for inclusion in Journal of Modern Applied Statistical Methods by an authorized editor of DigitalCommons@WayneState. 


\title{
Examining Growth with Statistical Shape Analysis and Comparison of Growth Models
}

\author{
Deniz Sigirli Ilker Ercan \\ Uludag University \\ Gorukle/Bursa, Turkey
}

Growth curves have been widely used in the fields of biology, zoology and medicine for assessing some measurable trait of an organism, such as height, weight, area or volume. In statistical shape analysis, a size measure is obtained using the geometrical information of an object as opposed to linear measurements. The performances of commonly used non-linear growth curves are compared by using centroid size as a size measure in a simulation study. An example is provided on the relationship between centroid size of the cerebellum and disease duration in multiple sclerosis patients.

Key words: Centroid size, growth models, statistical shape analysis.

Introduction

Many studies in the field of medicine are related to the examination of geometrical properties of an organ or organism. Although the data sets used in the statistical analyses of medical studies mainly consist of quantitative or qualitative measurement values, an organ or organism's appearance or shape is also used as input data via imaging techniques (Ercan, et al., 2012). Studies performed in medicine and biology commonly evaluate how the shape of an organ or organism is affected by a disease, how the shape is related to covariates such as sex, age or environmental conditions, the comparison of shapes, how to discriminate and classify using shape data, how to describe shape variability, how shape changes during growth and how shape is related to size (Dryden \& Mardia, 1998).

Deniz Sigirli is a Research Assistant in the Department of Biostatistics, Faculty of Medicine. Her research interests are statistical shape analysis and growth curves. Email her at: denizsigirli@hotmail.com. Ilker Ercan is a Professor in the Department of Biostatistics, Faculty of Medicine. His research interests are statistical shape analysis, reliability and validity analyses. Email him at: ercan@uludag.edu.tr.
Growth patterns can be defined as the composite of geometric changes in biological structure occurring through ontogenetic time (Lele \& Richtsmeier, 2001). These changes can be analyzed with growth curve models. The shapes of the growth curves show differences according to the organism type, environmental conditions and the nature of the trait being measured (Colak, et al., 2006). Growth curves seek a model with a biological basis and biologically interpretable parameters (Seber \&Wild, 2003).

Several authors have conducted studies in the areas of biology, medicine, zoology and agriculture by assessing some measurable trait of an organism, such as height, weight, area or volume (Carlson \& Baremore, 2005; Ersoy, et al., 2007; Karadavut, et al., 2010). In statistical shape analysis, the size measure is obtained by using the geometrical information of an object or an organism, as opposed to considering linear distances or measurements. One of the most commonly used size measures is centroid size. An important feature of centroid size is that it is statistically independent from the shape of the object; this is the only geometrical information that remains when location, scale and rotational effects are filtered out from an object (Dryden \& Mardia, 1998). This independence is not valid for other size measures, such as height, weight, area, volume, ratios or angles. 


\section{STATISTICAL SHAPE ANALYSIS AND COMPARISON OF GROWTH MODELS}

This study compares the performance of commonly used non-parametric growth curve models and examines their efficiency by sample size for each model using centroid size as a size measure. A practical example is given for examining the relationship between centroid size of the cerebellum and the duration of multiple sclerosis (MS) disease in MS patients with the three- and four- parameter logistic, Gompertz and Richards models.

\section{Growth Models}

$$
\text { Methodology }
$$

Some measure of the size of an object or living thing against time can be modeled using growth curves. In growth studies, both longitudinal and cross-sectional data can be used. Longitudinal data involve responses over time that can be modeled as a stochastic process (Lindsey, 1997). Cross sectional data consist of a group of measures for each age, but each individual is measured only once so that the sample for an age group does not contain any of the individuals in the previous age group. Longitudinal data are particularly useful in studying secular trends and are a requirement for predictive models of development. Alternatively, closely spaced longitudinal data may obscure more general patterns and reveal seemingly erratic, idiosyncratic patterns of individual growth. To study general population patterns, cross-sectional data may be more useful (Lele \& Richtsmeier, 2001).

A growth profile will generally be a nonlinear function of time, often reaching an asymptote. In this situation, linear models may not provide adequate explanations for growth; for these types of data, nonlinear models can provide better predictions. Different algorithms are used in nonlinear regression analysis, such as, the Levenberg-Marquardt, the Gauss-Newton and the Newton-Raphson algorithms (Bates \& Watts, 1988; Hintze, 2007). A general nonlinear regression model is:

$$
\begin{aligned}
& Y_{i}=f\left(X_{i} ; \theta\right)+\varepsilon_{i} \\
& i=1, \ldots, n .
\end{aligned}
$$

Such a model is reasonable to use with crosssectional data in which a single size measurement is obtained for each individual or experimental unit. In equation (1), $\theta$ is the predicted parameter's vector and $\varepsilon_{\mathrm{i}}$ is the independent and identically distributed error term with mean 0 and variance $\sigma^{2}$. The $X$, or independent variable, corresponds to age or another time variable, and $\mathrm{Y}$, the dependent variable, represents the related size measure. Parameters used in growth models $-\alpha, \beta, \kappa$, $\gamma$ and $\delta$ - have biological meanings. The $\alpha$ parameter represents the final size, this parameter also mathematically corresponds to the maximum asymptote point of the curve; $\beta$ is the initial size and corresponds to the minimum asymptote point of the curve; $\kappa$ is the parameter that shows the growth rate; $\gamma$ is the inflection point of the curve; and $\delta$ is the second inflection point, which is found in the Richards growth model (Seber \& Wild, 2003; Hintze, 2007).

Three Parameter Logistic Model

The three parameter logistic model is an $\mathrm{S}$ shaped function:

$$
\begin{aligned}
& f(x)=\frac{\alpha}{1+\beta e^{-k x}} \\
& -\infty<x<\infty .
\end{aligned}
$$

The curve has two asymptotes, when $\mathrm{x} \rightarrow-\infty$ as $\mathrm{f}(\mathrm{x})=0$ and when $\mathrm{x} \rightarrow \infty$ as $\mathrm{f}(\mathrm{x})=\alpha$. Growth typically begins prior to observation when $\mathrm{f}(\mathrm{x})>0$, this can create some difficulties. When $\mathrm{f}(\mathrm{x})=\alpha / 2, \mathrm{x}=\gamma$ is obtained and the growth rate reaches a maximum level.

Four Parameter Logistic Model

The four parameter logistic model is an extended form of the three parameter logistic model:

$$
f(x)=\gamma+\frac{\alpha-\gamma}{1+\beta e^{-\kappa x}} .
$$

The four parameter model is frequently used in bioassays or immunoassays, such as ELISAs or 


\section{DENIZ SIGIRLI \& ILKER ERCAN}

dose-response curves (Plikaytis \& Carlone, 2005; Wang, et al., 2008; Healy, 1972). In this logistic model, a monotonic function is either always increasing or decreasing for all values of $\mathrm{x}$.

\section{Gompertz Model}

The Gompertz model (Gompertz, 1825) was introduced to describe mortality rates in humans (Walter \& Bailer, 2005). According to Winsor (1932), Wright first suggested the use of the Gompertz curve for biological growth in 1926. The Gompertz growth curve is given by:

$$
f(x)=\alpha e^{\left\{-e^{-\kappa(x-\gamma)}\right\}} .
$$

\section{Richards Model}

Developed by Richards in 1959 as a generalization of the classical growth curves, the Richards model is a widely used and flexible growth model with four parameters. This model provides a flexible curve with an arbitrarily placed point of inflection.

$$
\begin{aligned}
& f(x)=\alpha\left[1+(\delta-1) e^{-\kappa(x-\gamma)}\right]^{\frac{1}{1-\delta}}, \\
& \delta \neq 1 .
\end{aligned}
$$

Other growth functions can be obtained from the Richards function according to the values that $\delta$ can take. When $\delta=0$, a monomolecular growth function is obtained; when $\delta=2$, a threeparameter logistic function is obtained; when $\delta=2 / 3$, and when $\delta \rightarrow 1$, a Gompertz growth function is obtained (Seber \& Wild, 2003; Hintze, 2007). The Gompertz, logistic and Richard's growth models have points of inflection and are sigmoid. These models are suitable for quantifying a growth phenomenon that exhibits a sigmoid pattern over time.

\section{Centroid Size}

If $\mathrm{X}_{\mathrm{k} \times \mathrm{m}}$ is a $\mathrm{k} \times \mathrm{m}$ configuration matrix (Cartesian coordinates of $\mathrm{k}$ landmarks in $\mathrm{m}$ real dimensions) of an object with $\mathrm{k}$ landmarks in $\mathrm{m}$ dimensions, then a size measure, $\mathrm{g}(\mathrm{X})$, is any positive, real value function of the configuration matrix, such that

$$
g(a X)=a g(X)
$$

for any positive scalar, a. The main size measures used in statistical shape analysis are centroid size, baseline size (as proposed by Galton) and the radius of the inscribed circle for the triangles (as proposed by Miles) (Dryden \& Mardia, 1998).

Centroid size is the most frequently used size measure in statistical shape analysis and is:

$$
\begin{aligned}
& S(X)=\|C X\|=\sqrt{\sum_{i=1}^{k} \sum_{j=1}^{m}\left(X_{i j}-\bar{X}_{j}\right)^{2}}, \\
& X \in R^{k m}
\end{aligned}
$$

where $\bar{X}_{j}=\frac{1}{k} \sum_{i=1}^{k} X_{i j}$ and $\|X\|=\sqrt{\operatorname{trace}\left(X^{\prime} X\right)}$ are the Euclidean norm; $\mathrm{C}$ is the centering matrix and is given by

$$
\mathrm{C}=\mathrm{I}_{\mathrm{k}}-\frac{1}{\mathrm{k}} 1_{\mathrm{k}} 1_{\mathrm{k}}{ }^{\prime}
$$

where $I_{k}$ is the $k \times k$ identity matrix and $1_{k}$ is the $\mathrm{k} \times 1$ vector of ones. Centroid size additionally can be identified as the square root of the sum of the variances of the landmarks around the centroid in $\mathrm{x}$ - and $\mathrm{y}$-directions as shown by:

$$
S(X)=\sqrt{\sum_{i=1}^{k}\left\|(X)_{i}-\bar{X}\right\|^{2}},
$$

where $(X)_{i}$ is the $i^{\text {th }}$ row of the $X$ matrix and $\overline{\mathrm{X}}=\left(\overline{\mathrm{X}}_{1}, \ldots, \overline{\mathrm{X}}_{\mathrm{m}}\right)$ is the centroid (Dryden \& Mardia, 1998).

Simulation

The original data set, which was used as the reference in the simulation study, consisted of 15 healthy individuals (4 male, 11 female). Corpus callosum (CC) images of these healthy individuals were obtained from the mid-sagittal sections of the magnetic resonance imaging (MRI) scans. The selected landmarks were marked on the digital images using TPSDIG 


\section{STATISTICAL SHAPE ANALYSIS AND COMPARISON OF GROWTH MODELS}

2.16 software (Rohlf, 2010). The mean, variance and other parameters used for data generation in the simulation study were obtained from this landmark coordinate data set.

The corpus callosum images of the individuals were divided into seven regions according to Witelson's sub-division framework (Witelson, 1989). For the growth curve models, $5^{\text {th }}$ and the $6^{\text {th }}$ regions were combined and analyzed together as one region. A total of 5 landmarks were marked for that region (landmarks 1, 2, 4, 5 and 6). The first 4 landmarks (1, 2, 3 and 4) are the anatomical landmarks defined as in Ozdemir, et al. (2007). To better describe the shape of the brain structure, two additional landmarks (5 and 6) were constructed by referencing these anatomical landmarks. The third landmark was not included in the study but was used in the determination of landmarks 5 and 6 (see Figure 1 ); a descriptive list of the landmarks is provided in Table 1.

Using age as an independent variable and centroid size as the dependent variable, different growth models were constructed using the original data set. These models are:
1. The three parameter logistic model:

$$
\mathrm{y}=\frac{(11838.440)}{1+(85.084) \mathrm{e}^{-(-1.124) \mathrm{x}}}+\mathrm{e}
$$

2. The four parameter logistic model:

$$
\mathrm{y}=(362757.700)+\frac{(92,119-362757.700)}{1+(1.788) \mathrm{e}^{-(0.427) \mathrm{x}}}+\mathrm{e}
$$

3. The Gompertz model:

$$
\mathrm{y}=(8953.636) \mathrm{e}^{\left(-\mathrm{e}^{-(-0.002)(\mathrm{x}-(-584.773))}\right)}+\mathrm{e}
$$

4. The Richards model:

$$
\begin{aligned}
& \mathrm{y}= \\
& 304.851\left[1+(14.756-1) \mathrm{e}^{-(-0.153)(\mathrm{x}-(-54.227))}\right]^{1 /(1-14.756)}+\mathrm{e}
\end{aligned}
$$

In the simulation study, the $\mathrm{x}$ values (age) were generated from a normal distribution

Figure 1: The Sub-Divisions of the Corpus Callosum Based on the Witelson Framework and the Landmarks Marked on the $5^{\text {th }}$ and $6^{\text {th }}$ Regions

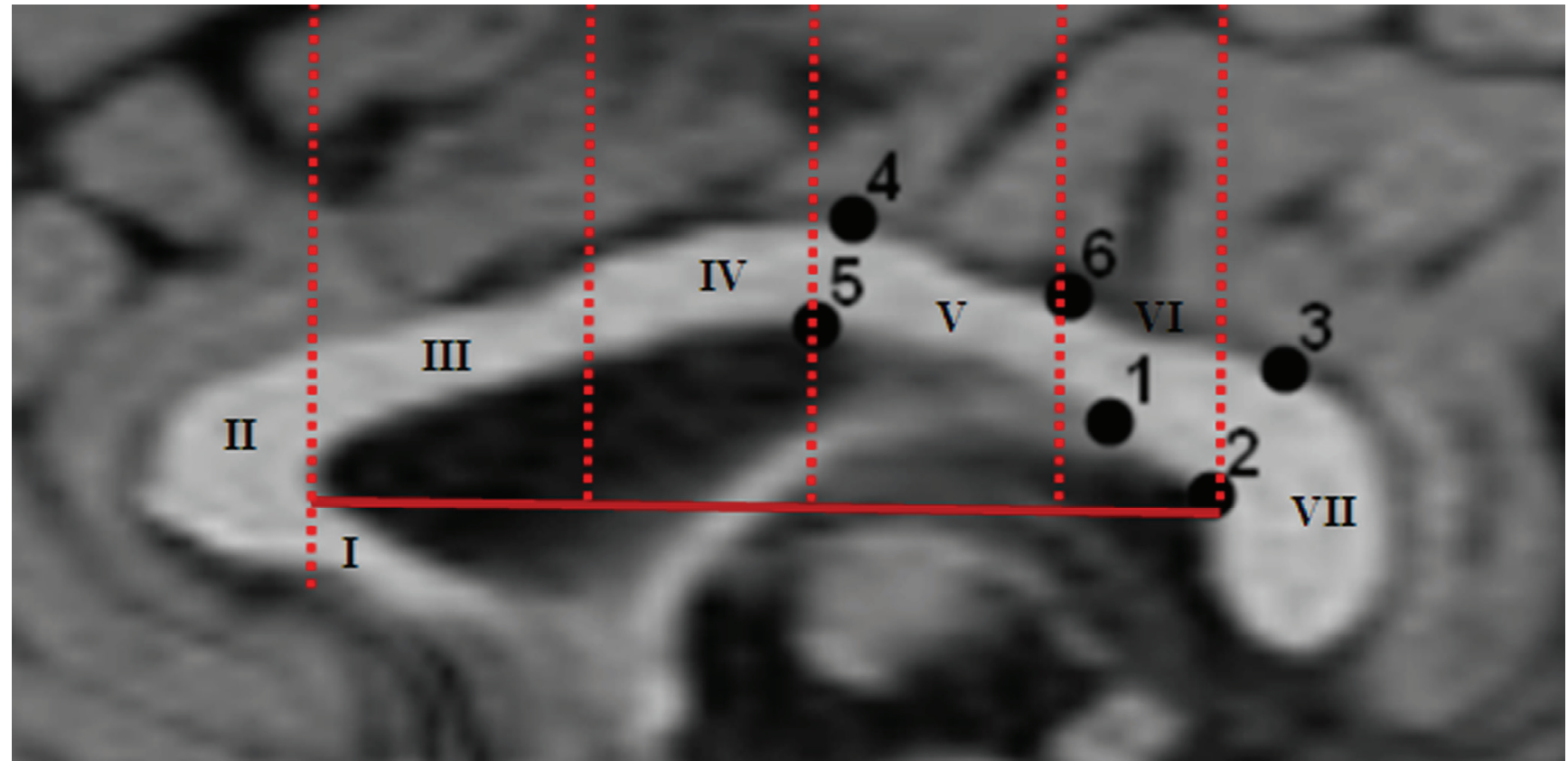


DENIZ SIGIRLI \& ILKER ERCAN

Table 1: A Descriptive List of the Landmarks Used For the Corpus Callosum (CC)

\begin{tabular}{|cl|}
\hline Landmark Number & \multicolumn{1}{c|}{ Landmark Definition } \\
\hline 1 & CC-fornix junction
\end{tabular}

by using the mean and the variance of the age values from the original data set for each model, and error terms, e $\sim \mathrm{N}(0,1)$, were generated. The dependent variable's values (centroid size) were generated using values from the models obtained from the original data set. Simulations were performed for sample sizes $\mathrm{n}=20,50$ and 100 with 250 repetitions.

\section{Results}

To compare the performance of the growth models, mean square error (MSE) criteria were used as given in equation (5). (See Table 2 and Figures 2-3 for MSE values.) The MSE is:

$$
\operatorname{MSE}=\frac{1}{\mathrm{t}} \sum_{\mathrm{j}=1}^{\mathrm{t}}\left(\frac{\sum_{\mathrm{i}=1}^{\mathrm{n}}\left(\mathrm{y}_{\mathrm{ij}}-\hat{\mathrm{y}}_{\mathrm{ij}}\right)^{2}}{\mathrm{n}-\mathrm{p}}\right)
$$

where $t$ is the number of replications, $p$ is the number of parameters in the model and $n$ is the sample size in each repetition.
To investigate the efficiencies of the parameter estimates according to sample size, the mean absolute deviations (MAD) and the bias of the estimated coefficients criteria were used. These two criteria were used only to examine each model's performance in itself according to change in the sample size.

To show the difference between the predicted and the actual values of the parameters, the MAD criteria were calculated as:

$$
\mathrm{MAD}=\frac{1}{\mathrm{t}} \frac{1}{\mathrm{p}} \sum_{\mathrm{i}=1}^{\mathrm{t}} \sum_{\mathrm{j}=1}^{\mathrm{p}}\left|\hat{\beta}_{\mathrm{ij}}-\beta_{\mathrm{j}}\right|
$$

where $t$ is the number of replications, $p$ is the number of parameters in the model, $\mathrm{n}$ is the sample size in each repetition, $\hat{\beta}_{\mathrm{ij}}$ is the predicted value of the $j^{\text {th }}$ parameter in the $i^{\text {th }}$ model and $\beta_{j}$ is the actual value of the $j^{\text {th }}$ parameter. (See Table 3 and Figure 4.) 
STATISTICAL SHAPE ANALYSIS AND COMPARISON OF GROWTH MODELS

Table 2: MSE Values for Growth Models

\begin{tabular}{|c|c|c|c|c|}
\hline $\mathrm{n}$ & Three Parameter Logistic & Four Parameter Logistic & Gompertz & Richards \\
\hline 20 & 1.06808 & 1.0752 & 1.05095 & 1.42999 \\
\hline 50 & 1.01298 & 1.01018 & 1.00929 & 1.03037 \\
\hline 100 & 0.95822 & 0.96118 & 0.95646 & 0.96734 \\
\hline
\end{tabular}

Figure 2: MSE Values for Growth Models

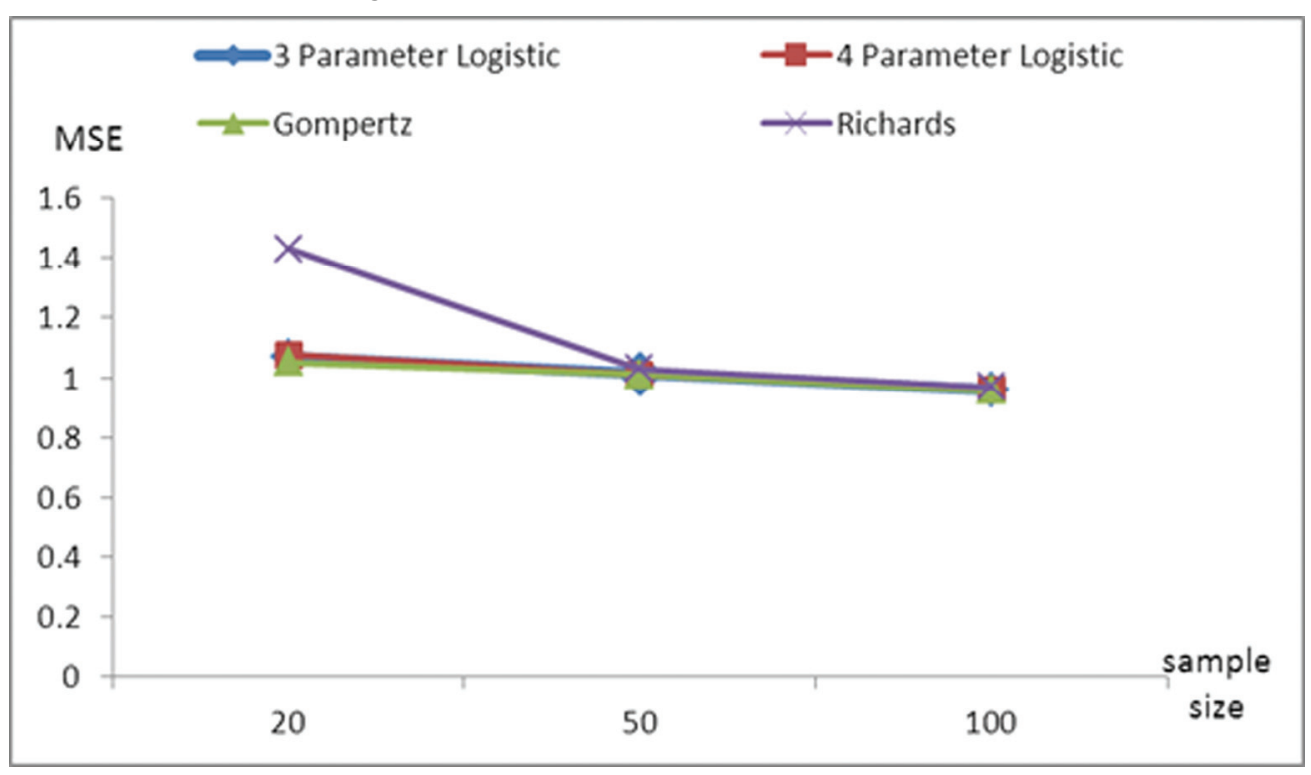

Figure 3: Percentage Change for MSE Values

\begin{tabular}{|c|c|c|c|c|c|}
\hline MSE (\% & $\begin{array}{l}3 \text { Parameter } \\
\text { b) Logistic }\end{array}$ & $\begin{array}{l}4 \text { Parameter } \\
\text { Logistic }\end{array}$ & Gompertz & Richards & \\
\hline $\begin{array}{l}-0.05 \\
-0.10\end{array}$ & -0.05 & -0.06 & -0.04 & & \\
\hline-0.15 & -0.10 & -0.11 & -0.09 & & $\begin{array}{l}\square n=50 \\
\square n=100\end{array}$ \\
\hline $\begin{array}{l}-0.20 \\
-0.25\end{array}$ & & & & & \\
\hline-0.30 & & & & -0.28 & \\
\hline-0.35$]$ & & & & -0.32 & \\
\hline
\end{tabular}


DENIZ SIGIRLI \& ILKER ERCAN

Table 3: MAD Values for Growth Models

\begin{tabular}{|c|c|c|c|c|}
\hline $\mathrm{n}$ & Three Parameter Logistic & Four Parameter Logistic & Gompertz & Richards \\
\hline 20 & 3061.241 & 5438899 & 2076.513 & 374.8195 \\
\hline 50 & 3007.479 & 372227.4 & 1954.277 & 330.3648 \\
\hline 100 & 2986.007 & 299968 & 1997.179 & 96.05916 \\
\hline
\end{tabular}

Figure 4: Percentage Changes for MAD Values

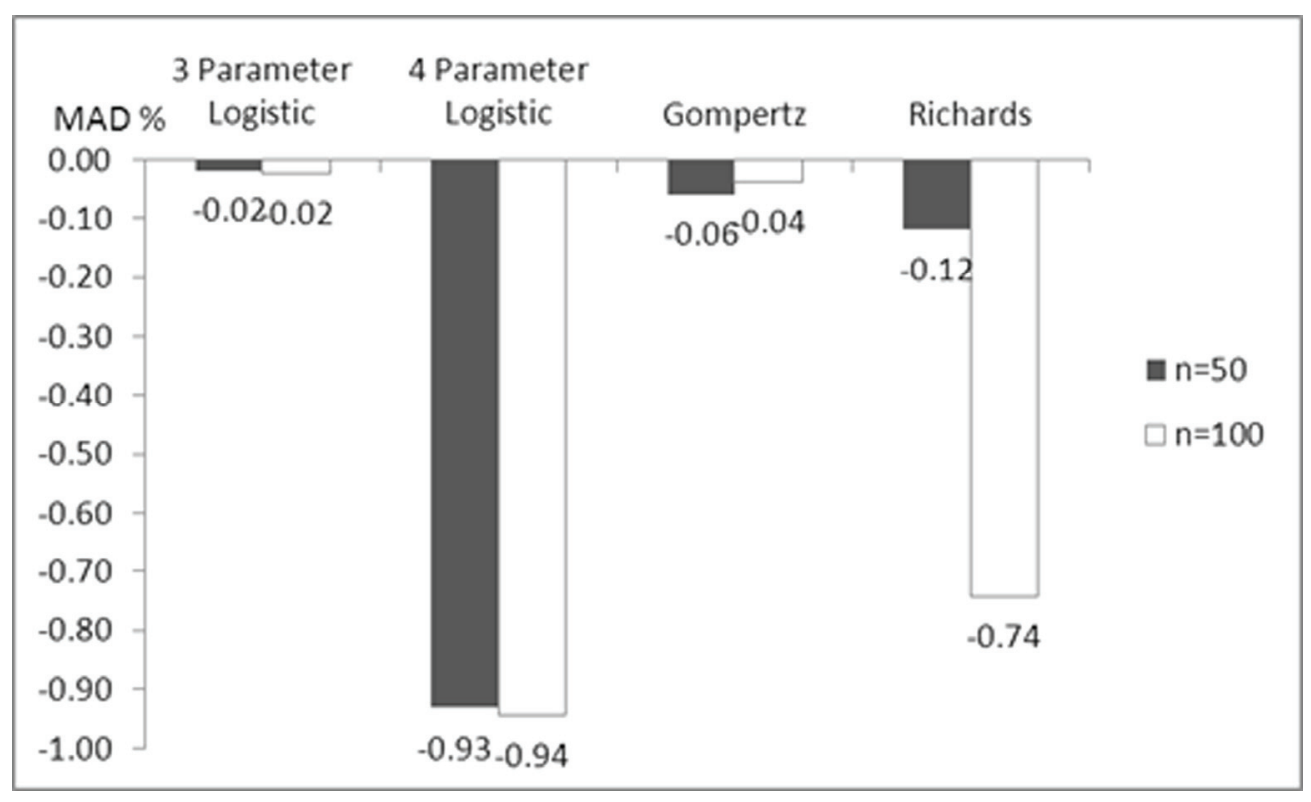

To show the difference between the mean of the predicted values and the actual values of the parameters, the bias criteria were calculated using

$$
\operatorname{Bias}=\frac{1}{p} \sum_{j=1}^{p}\left|\frac{\sum_{i=1}^{t} \hat{\beta}_{i j}}{t}-\beta_{j}\right|
$$

where $t$ is the number of replications, $p$ is the number of parameters in the model, $\mathrm{n}$ is the sample size in each repetition, $\hat{\beta}_{\mathrm{ij}}$ is the predicted value of the $j^{\text {th }}$ parameter in the $i^{\text {th }}$ model and $\beta_{j}$ is the actual value of the $j^{\text {th }}$ parameter. (See Table 4 and Figure 5.)

Practical Example

The data set used in this example consists of the MRI scans of 44 (17 (38.64\%) male, 27 female $(61.36 \%))$ multiple sclerosis (MS) patients. The mean age was $32.07 \pm 8.46$ (mean \pm standard deviation) years. The median duration of the MS disease was 25 (4-72) months (median (min-max)). All MS patients fit the McDonald, et al., 2001 criteria. An institutional review board approved the retrospective study and all participants gave informed consent prior to the start of the study. 
STATISTICAL SHAPE ANALYSIS AND COMPARISON OF GROWTH MODELS

Table 4: Bias Values for Growth Models

\begin{tabular}{|c|c|c|c|c|}
\hline $\mathrm{n}$ & Three Parameter Logistic & Four Parameter Logistic & Gompertz & Richards \\
\hline 20 & 3009.35 & 5392501 & 2063.3 & 339.116 \\
\hline 50 & 3007.48 & 240113 & 1954.28 & 279.614 \\
\hline 100 & 2953.82 & 157085.5 & 1996.45 & 46.7993 \\
\hline
\end{tabular}

Figure 5: Percentage Changes for Bias Values

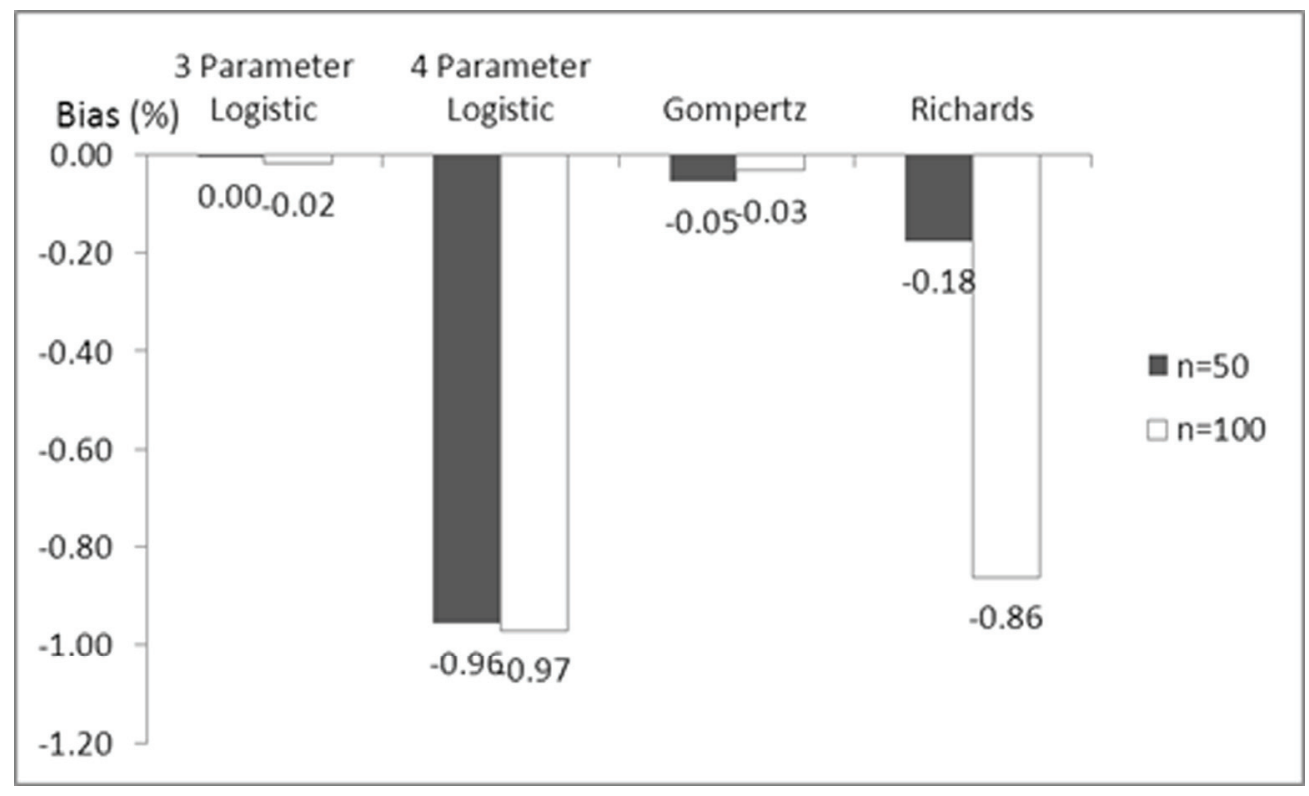

Eight midline cerebellar landmarks were selected from the image of the mid-sagittal plane (see Figure 6). The landmarks were chosen on the basis of reliability, significant anatomical coverage and previous cerebellar morphological descriptions in MS patients. A descriptive list of these anatomical landmarks is provided in Table 5. The relationship between centroid size of cerebellum and the duration of the MS disease was examined using the three and four parameter logistic, Gompertz and Richards models. The mean squared error and $R^{2}$ for the models are shown in Table 6 .

Among the models of the studied relationship, the Gompertz model and three parameter logistic model had lower MSE values, while the four parameter logistic model had the highest $R^{2}$ value. All models significantly predicted the relationship between centroid size and the duration of disease. Figures 7-10 show that a decrease occurs in the cerebellum size of the MS patients as the duration of disease increases.

\section{Conclusion}

With the technological advances in the fields of biology and medicine, different methods have been developed to analyze an organ's or an organisms' forms by recording the geometrical locations of landmarks. Statistical shape analysis plays an important role in such studies. 


\section{DENIZ SIGIRLI \& ILKER ERCAN}

Figure 6: T1-Weighted Mid-Sagittal Slice Demonstrating the Cerebellar Landmarks

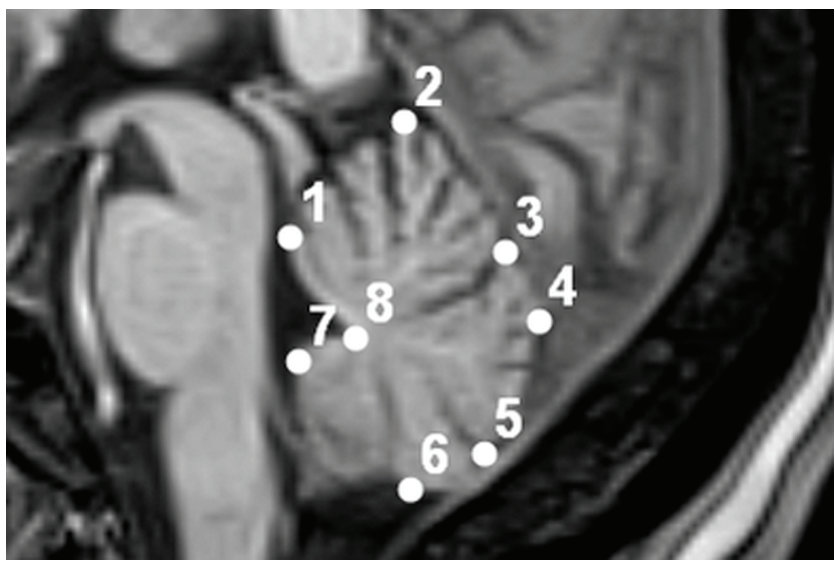

Table 5: Descriptive List of the Landmarks Used for the Cerebellum

\begin{tabular}{|c|c|}
\hline Landmark Number & Landmark Definition \\
\hline 1 & Velum medullare superius angulation-cerebellar outline junction \\
\hline 2 & Superior cerebellum \\
\hline 3 & Primary fissure- cerebellar outline junction \\
\hline 4 & Posterior cerebellum \\
\hline 5 & Prepyramidal fissure- cerebellar outline junction \\
\hline 6 & Inferior cerebellum \\
\hline 7 & Velum medullare inferius angulation-cerebellar outline junction \\
\hline 8 & Fastigium cerebelli \\
\hline
\end{tabular}

Table 6: Growth Models of the Relationship between Cerebellum Size and Disease Duration*

\begin{tabular}{|c|c|c|c|c|}
\hline Model & Predicted Equation & $R^{2}$ & MSE & p-value \\
\hline $\begin{array}{c}\text { Three } \\
\text { Parameter } \\
\text { Logistic }\end{array}$ & $\mathrm{CS}=\frac{(3.89)}{1+(0.35) \mathrm{e}^{-(-0.009) \mathrm{DD}}}+\mathrm{e}$ & 0.26992 & 0.04849 & 0.00158 \\
\hline $\begin{array}{c}\text { Four } \\
\text { Parameter } \\
\text { Logistic }\end{array}$ & $\mathrm{CS}=(3.37)+\frac{(1.57-3.37)}{1+(0.37) \mathrm{e}^{-(-0.017) \mathrm{DD}}}+\mathrm{e}$ & 0.26993 & 0.04970 & 0.00524 \\
\hline $\begin{array}{c}\text { Gompertz } \\
\text { Richards }\end{array}$ & $\mathrm{CS}=(159.47) \mathrm{e}^{\left(-\mathrm{e}^{-(-0,006)(\mathrm{DD}-(4.27))}\right)}+\mathrm{e}$ & 0.26992 & 0.04849 & 0.00158 \\
\hline
\end{tabular}

*CS: centroid size; DD: disease duration; $R^{2}$ : the coefficient of determination; MSE: Mean Squared Error 
Figure 7: Three Parameter Logistic Model

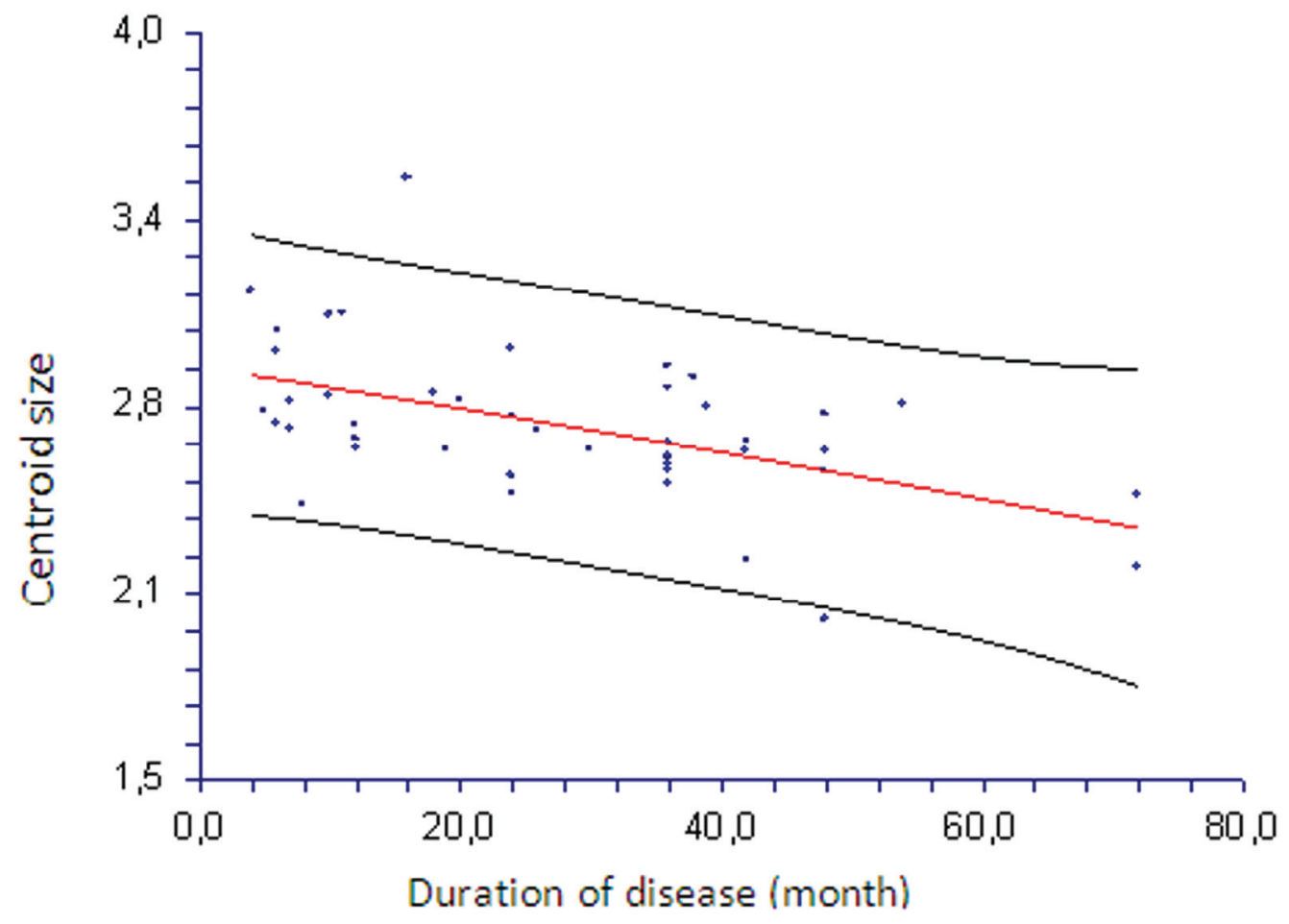

Figure 8: Four Parameter Logistic Model

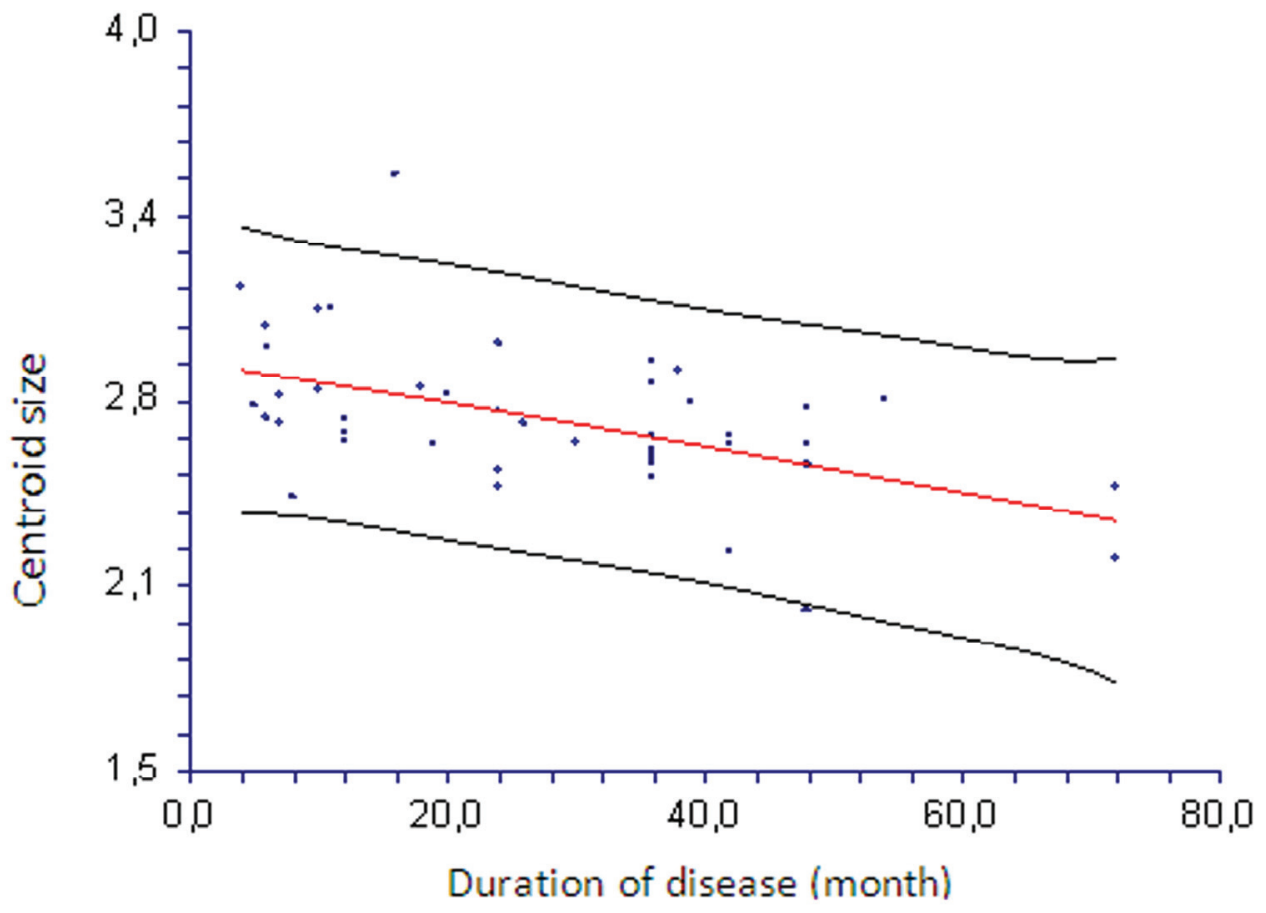


DENIZ SIGIRLI \& ILKER ERCAN
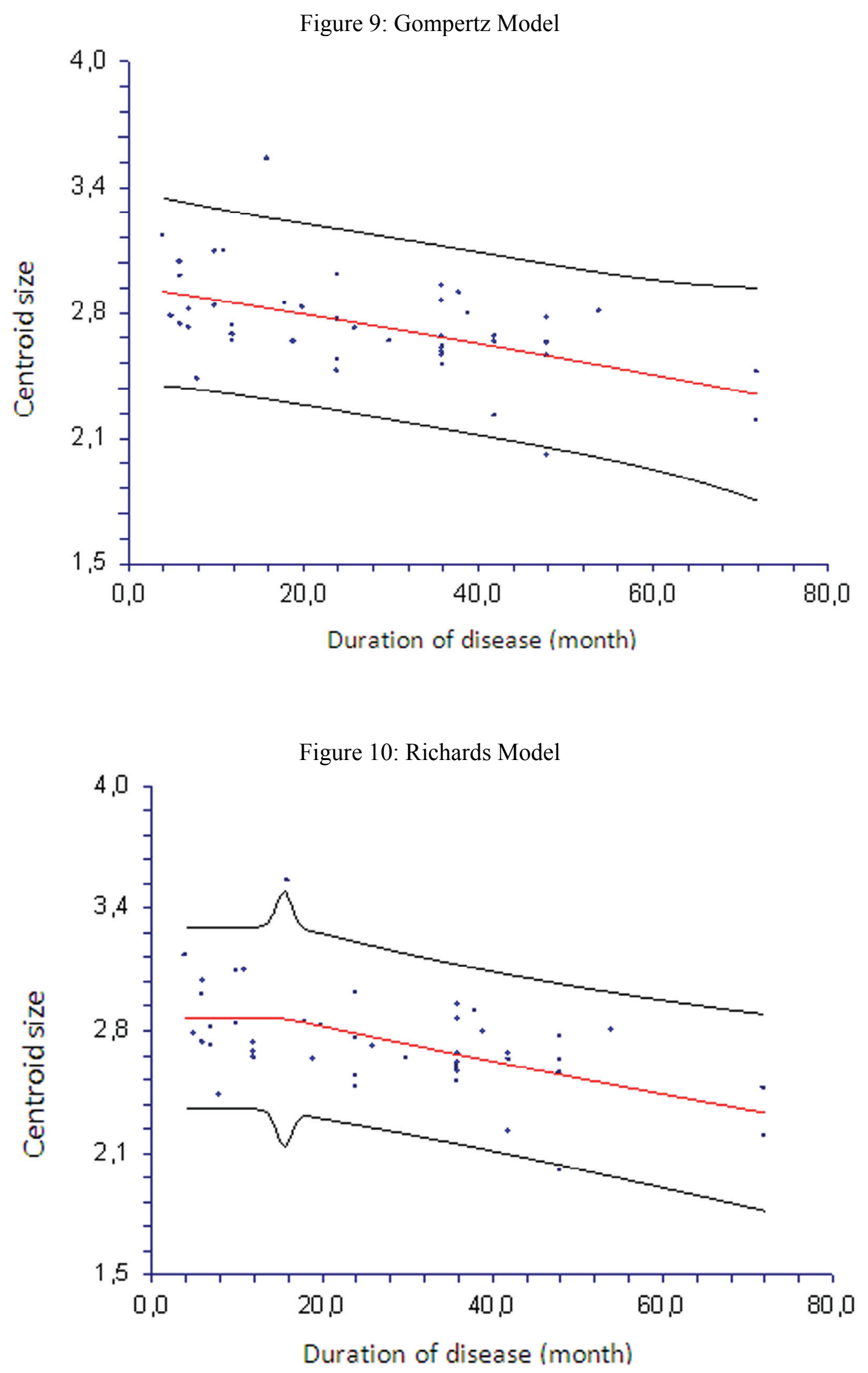


\section{STATISTICAL SHAPE ANALYSIS AND COMPARISON OF GROWTH MODELS}

Biological processes, such as disease or injury, ontogenetic development or adaptation to local geographic factors can cause shape differences between individuals. These differences in shape may signal differences in the processes of growth and morphogenesis. A shape analysis is one approach to understanding the diverse causes of variation and morphological transformation (Zelditch, 2004).

Growth studies produce important information on aspects of the biology of an organism, such as the genetic basis of morphogenesis, the phylogenetic underpinnings of developmental patterns or the role of hormones, teratogens, dietary elements and other environmental variables on the growth processes (Lele \& Richtsmeier, 2001). The relationship between a measurable trait of an organism and time can be modeled with a growth curve. Several applied studies have been performed using growth curves and taking a measurable trait such as area, length, weight or volume as a size measurement (Carlson \& Baremore, 2005; Ersoy, et al., 2007; Karadavut, et al., 2010; Ozel \& Ertekin, 2001); however, in a statistical shape analysis, size measurement is obtained by using geometrical information about an object or organism. One commonly used size measure in shape analysis is centroid size (Dryden \& Mardia, 1998). An important feature of centroid size is that it is independent from the shape; this feature is not valid for the other size measures, such as length, weight, area or volume.

This study used centroid size, as opposed to the classical measurements used in nonlinear growth curves. In the literature, especially in the field of geometric morphometry, several studies have investigated the relationship between size and age. In these studies, linear models have usually been used with the natural logarithm of the centroid size as the dependent variable and age as the independent variable. The only study in the literature where non-linear growth models were used with centroid size was the size measure study by Colak, et al. (2011). This illustrates the necessity of investigating the performance of non-linear growth models where centroid size is the dependent variable. Cardini and Elton (2007) investigated the effect of sample size on geometric morphometric studies of size and shape; they note that sampling error might affect estimates of the statistical parameters - this observation was virtually absent in geometric morphometrics and few studies have performed simulations and mathematical modeling to theoretically examine the issues (Cardini \& Elton, 2007). It appears that this is the first study to compare non-linear growth models according to sample size by using centroid size as a size measure.

\section{Summary}

In all growth models examined in this study, the MSE decreased as the sample size increased. The Richards model had the largest MSE values in small sample sizes of all the models. As the sample size increased, the MSE value of the Richards model become lower, reaching a comparable value to the MSE values of the other models. Therefore, the Richards model is not suitable for small sample sizes. The Gompertz model and the three and four parameter logistic models had similar MSE values for all sample sizes and experienced similar effects from the decrease of sample size. Except in the small sample size condition, there were no major differences between the models in terms of MSE values.

When the growth curves were assessed in terms of the MAD measure, there was a decrease in the MAD values of the Richards model and the three parameter and four parameter logistic models; however, there was a slight increase in the MAD value of the Gompertz model as sample size increased. The three parameter logistic and Gompertz models showed the lowest decrease in MAD as sample size increased. The four parameter logistic model experienced the largest effects from changes in sample size and exhibited the largest percent change decrease in its MAD value. While transitioning from a moderate to a large sample size, the Richards model showed a significant decrease in MAD value, but the Richards model did not show a remarkable decrease in transitioning from a small to a moderate sample size.

Results for the bias measure were similar to the results for the MAD measure. Although a decrease was observed in the bias values of the Richards model and the three and 


\section{DENIZ SIGIRLI \& ILKER ERCAN}

four parameter logistic models, there was a small increase in the bias value of the Gompertz model in transitioning to a large sample size. The models that showed the smallest decrease in bias with the increase in the sample size were the three parameter logistic model and the Gompertz model. The four parameter logistic model was the model most affected by sample size, and it was the model that had the largest decrease in its bias value. When transitioning from a moderate to a large sample size the Richards model showed a large decrease in bias but it did not show a remarkable decrease in transitioning from a small to a moderate sample size.

Generally, the Richards model is not convenient for small samples in terms of both model performance and parameter estimates. The three parameter logistic and Gompertz models do not display differences in parameter estimates by sample size, therefore, the three parameter logistic and Gompertz models are preferable to the other two models, particularly for small samples.

\section{References}

Bates, D. M., Watts, D. G. (1988). Nonlinear Regression Analysis and Its Applications. New York, NY: John Wiley \& Sons.

Cardini, A., \& Elton, S. (2007). Sample size and sampling error in geometric morphometric studies of size and shape. Zoomorphology, 126, 121-134.

Carlson, J., \& Baremore, I. (2005). Growth dynamics of the spinner shark (Carcharhinus brevipinna) off the United States southeast and Gulf of Mexico coasts: A comparison of methods. Fishery Bulletin, 103, 280-291.

Colak, C., Orman, M. N., \& Ertugrul, O. (2006). Simple linear and logistic growth model for the body measurements of Simmental $x$ Southern Anatolian Red crossbred cattle. Veterinary Journal of Ankara University, 3, 195199.
Colak, C., Ercan, I., Dogan, M., Ozdemir, S. T., Sener, S., \& Alkan, A. (2011). Detecting the shape differences of the corpus callosum in Behçet's disease by statistical shape analysis. Anatomical Records, 294, 870-874.

Dryden, I. L., \& Mardia, K. V. (1998). Statistical shape analysis. New York, NY: Wiley.

Ercan, I., Ocakoglu, G., Sigirli, D., \& Ozkaya, G. (2012).Statistical shape analysis and usage in medical sciences. Turkiye Klinikleri Journal of Biostatistics, 4(1), 27-35.

Ersoy, L., Mendes, M., \& Keskin, S. (2007). Estimation of parameters of linear and nonlinear growth curve models at early stage in California turkeys. Archiv fur Geflugelkunde, 71, 175-180.

Healy, M. J. R. (1972). Statistical analysis of radioimmunoassay data. Biochemical Journal, 130, 207.

Hintze, J. (2007). NCSS and PASS: Number cruncher statistical systems. Utah: NCSS Statistical \& Power Analysis Software Publications.

Karadavut, Palta, U. C., Kokten, K., \& Bakoglu, A. (2010). Comparative study on some non-linear growth models for describing leaf growth of maize. International Journal of Agricultural Bilogy, 12, 227-230.

Lele, S., Richtsmeier, J. T. (2001). An invariant approach to statistical analysis of shapes. Florida: Chapman \& Hall/CRC Press.

Lindsey, J. K. (1997). Applying generalized linear models. New York, NY: Springer Verlag.

McDonald, W. I., Compston, A., Edan, G., Goodkin, D., Hartung, H.P., Lublin, F.D., McFarland, H. F., Paty, D. W., Polman, C. H., Reingold, S. C., Sandberg-Wollheim, M., Sibley, W., Thompson, A., Van Den Noort, S., Weinshenker, B. Y., Wolinsky, J. S. (2001). Recommended diagnostic criteria for multiple sclerosis: guidelines from the International Panel on the diagnosis of multiple sclerosis. Annals of Neurology, 50(1), 121-127. 


\section{STATISTICAL SHAPE ANALYSIS AND COMPARISON OF GROWTH MODELS}

Ozdemir ,S. T., Ercan, I., Sevinc, O., Guney, I., Ocakoglu, G., Aslan, E., \& Barut, C. (2007). Statistical shape analysis of differences in the shape of the corpus callosum between genders. Anatomical Records, 290, 825-830.

Ozel, H. B., \& Ertekin, M. (2011). Growth models in investigating oriental beech (Fagus orientalis Lipsky.) juvenilities growth performance in the Western Black Sea in Turkey (Devrek-Akçasu Case Study). Romanian Biotechnological Letters, 16, 5851.

Plikaytis, B.D., Carlone, G.M. (2005). Statistical considerations for vaccine immunogenicity trials. Part 1: introduction and bioassay design and analysis. Vaccine. 23: 15961605.

Rohlf, F. J. (2010). TPSDIG Version 2.16. New York: Ecology and Evaluation, SUNY at Stony Brook.

Seber, G. A. F., \& Wild, C. J. (2003). Nonlinear regression. Hoboken, NJ: John Wiley $\&$ Sons.
Walter, W. P., \& Bailer, A. J. (2005). Analyzing environmental data. Statistical Papers, 51, 1009-1010.

Wang, D., Burton, R. L., Nahm, M. H., \& Soong, S. J. (2008). A four-parameter logistic model for estimating titers of functional multiplexed pneumococcal opsonophagocytic killing assay. Journal of Biopharmaceutical Statistics, 18, 307-325.

Winsor, C. P. (1932). The Gompertz curve as a growth curve. Proceedings of the National Academy of Sciences, 18(1), 1-8.

Witelson, S. F. (1989). Hand and sex differences in the isthmus and genu of the human corpus callosum. Brain, 112, 799.

Zelditch, M. (2004). Geometric morphometrics for biologists: A primer. New York, NY: Elseiver Academic Press. 